\title{
GAM-APT: A SERIOUS GAME ATTRIBUTE TAXONOMY FOR ADVANCED PERSISTENT THREATS
}

\author{
Mathew Nicho \\ College of Technology Innovation, Zayed University, Dubai, United Arab Emirates
}

\begin{abstract}
Serious games find immense applications in the domain of education, information systems and information security due to convenience of time, instant feedback, attractiveness and the ease of simulating novel and multiple attack scenarios. Initially created for military purposes, it emerged as a promising approach to self-train computer users in changing their profile from a 'weakest link' to a 'strong link' in the network chain. In this respect, training computer users on advanced persistent threats (APT) vectors which deploys simple social engineering yet complex technical methods to exploit internetworked computer user and subsequent vulnerabilities is a challenging task. While commercial and academic efforts in technical cyber security tools and models along with awareness and training has contributed to its abatement to some extent, the increase in successful attacks pose serious questions on the effectiveness of existing user awareness and training methods. While serious games and models have been proposed by researchers in cyber security domain, attributes for building a serious gaming model for APT is wanting in both academic and practitioner domains. In this respect, we propose a serious game taxonomy GAM-APT by integrating the serious gaming model components namely the 'player', 'game' and 'knowledge' dimensions with Gagne's nine events using the serious gaming taxonomy.
\end{abstract}

\section{KEYWORDS}

Phishing, Advanced Persistent Threats, Serious Games

\section{INTRODUCTION}

Serious games are advocated as promising technologies supporting training and increasing skills necessary to deal with new, complex and unexpected situations (Heldal, Wijkmark et al., 2016). Serious games which were initially created for military purposes, subsequently was extended to educational and business world including health care testing, emergency resolution, corporate training, virtual tour, education as well as creating behavioral change (Yang, 2018). Since cyber-attacks exploit human element of security, there is a compelling need to educate and train users on how to protect themselves from cyber threats (VanSteenburg, 2017). Computer games are attractive to many young generations of computer users as it might be effective to keep motivating them to learn. Serious games which are attractive to young computer users have become an effective method of simulation-based learning and training in a dynamically changing world of complex cyber security issues (Furuichi and Aibara, 2019).

Deploying 'zero day' malware or near 'zero day' malware, APT as it name implies use advanced techniques; remains persistent in its attack including thwarting attempts by anti-malware tools in detection and elimination; and uses apparently simple (social engineering) but complex (cyber technological) methods to gain privileged entry, escalate privileges and subsequently exfiltrate data via the opened backdoor. As the entry of APT is normally via the computer user interface, the above APT perspective provides a socio-technical dimension to the APT problem. This socio vulnerability makes APT a predominantly a socio issue where excessive reliance solely on cyber technological countermeasures is inadequate. Hence training the computer user through the use of simulated attacks (multiple APT user interface attack scenarios) combined with defensive (detective, preventive, responsive) strategies (DS) by means of serious games can enhance user's capabilities for DS.

The paper is structured as follows. Section II discuss the user perspectives in APT while section III explores serious games from the perspective of history, objectives, research, user decisions and models. Section IV presents the GAM-APT taxonomy of attributes, followed by conclusion (section V). The 
remainder of the paper uses the term 'user' or 'employee' to signify 'organizational internetworked computer user'. 'Threats' refer to advanced persistent threats using APT tools and vectors. 'Security' refers to information systems security in organizations.

\section{USER PERSPECTIVES IN APT}

APT attacks happen due to a combination of hacker skills and the inadvertent behavior of computer users. Advanced Persistent Threats (APTs) as the name implies use multiple social engineering techniques (Parthy \& Rajendran, 2019), while employing advanced cyber hacking techniques on cyber-physical systems; remains persistent till its successful and proceeds to deploy potent zero-day malware threat on the compromised cyber-physical asset. Since its emergence in the early half of the twenty first century, the potent nature of the threat as well as the frequency of attack targeted at critical organizations has not decreased, despite advances in network security and cyber defenses. In this respect, analysis of multiple APT attacks has pointed out the user vulnerabilities (Alshamrani, Myneni, Chowdhary, \& Huang, 2019) in opening a security hole paving the way for asset compromise, privilege escalation and subsequent exfiltration. Hence, users pay a vital role in securing the weakest link in the security chain.

APTs have emerged as a significant security threat as well as challenge for a cyber- physical system due to their stealthy, dynamic, persistent and adaptive nature (Huang \& Zhu, 2020). APT is a serious issue for current detection methods because the common defensive methods deployed by organizations, depend on known signatures of attacks, while APTs make heavy use of unknown security holes for attacks which makes detection challenging. Furthermore, errors and omissions, sabotage caused by employees, criminal agent, industrial or commercial espionage and malicious programs combined make this threat potent and successful (Rodríguez-Corzo, Rojas, \& Mejía-Moncayo, 2018). Hence, organizations ought to take steps to ensure that their employees are made aware of sensate information which should not be shared via the Internet in answer to unexpected requests (Furnell, 2013). In this respect, serious games have emerged as a new approach that can complement instruction-led or computer-based security training where players learn and practice cyber security concepts through the game (Hart, Margheri, Paci, \& Sassone, 2020).

\section{SERIOUS GAME}

The global serious games market which was valued at $\$ 2,731$ million in 2016 , is expected to reach $\$ 9,167$ million by 2023 (Sonawane, 2017). Since researchers began designing simple games and simulations as part of their research in the early 1950s, games have evolved to become an effective mode of learning. However, it was 'Odyssey' by Magnavox, one of the world's first commercial home video game consoles (launched in the USA in 1972), that emphasized the device's potential as an educational tool, and thus might be considered one of the first serious video game (Laamarti, Eid, \& El Saddik, 2014). Simultaneously, in 1970, Clark published the concepts of using serious games where he emphasized the use of games in education, occupational choice and training, including problem solving in government and industry (Clark, 1970).

\subsection{Objectives of Serious Games}

In contrast to entertainment games, serious games are games which have been intentionally designed to support learning (Boyle et al., 2014). Serious games not only assists in assessing higher order thinking skills, which is a necessary step to improve them (Laamarti et al., 2014), but also improve skill of knowledge, rehabilitation, medical treatments, training and education (Furuichi \& Aibara, 2019). This is mainly due to its ability to provide interactive environments that are complex and open for exploration that learners can use to demonstrate and expand their skills, and assessment (Van Voorhis \& Paris, 2019). Being a mental contest played with computer in accordance with specific rules that uses entertainment to further government or corporate training, education, or health (L. Yang, 2018), these games are designed to include cognitive activities to assure participants' engagement levels remain high (Salameh, 2019). Serious games has proved that effective learning is most 'effective' when it is active, experiential, situated, problem-based and when it 
provides immediate feedback (Connolly, Boyle, MacArthur, Hainey, \& Boyle, 2012). Subsequently, serious games are advocated as promising technologies supporting training and increasing skills necessary to deal with new, complex and unexpected situations (Heldal, Wijkmark, \& Pareto, 2016).

\subsection{Serious Games in Cybersecurity}

Security education and training awareness (SETA) programs have a defined objective of ensuring behavioral change in the participant's use of computer systems. In this respect, serious games contains easy to understand objectives, continuous assessment and feedback, and narratives that provide the player with sense of identity (VanSteenburg, 2017). Hence, serious games are effective methods of simulation based learning and training in a dynamically changing world of cyber security issues (Furuichi \& Aibara, 2019). However, since 'hacking' in cyber domain involves competing players where the 'hacker' tries to penetrate the 'victim's computer while the victim intentionally or unintentionally attempts to defend her/his IS assets, serious games in cyber security thus follows a competing pattern. Saunders (2001) has classified activity simulation in the information security domain into five categories namely 1) Packet Wars, 2) Sniffers \& Network Design Tools, 3) Canned Attack/Defend Scenarios, 4) Management Flight Simulators, and 5) Role-playing. Training and education in serious games in cyber security involve presenting multiple scenarios to the trainee. In this respect serious games for training computer users on APT attacks and defense comes under the 'attack/defend scenario'.

\subsection{Research on Serious Games in Cybersecurity}

From a user perspective (socio) research has been done focusing on traditional, hands-on, and game-based training of computer users. With serious games gaining popularity to train computer users, a survey on serious games in cyber security training by Tioh, Mina, and Jacobson (2017) listed eighteen papers on innovative serious games for cyber security with thirteen serious games available for user training on the Internet. However, the emphasis on these games focus more on generic cyber security, phishing, and spear-phishing rather than on APT. A search on google scholar for APT user training games using the term "serious games" and "advanced persistent threats" (from 2015 to 2020) turned up only seven papers (Feng, Xiong, Niyato, \& Wang, 2019; Huang \& Zhu, 2020; Katsantonis, Kotini, Fouliras, \& Mavridis, 2019; Luh, Temper, Tjoa, Schrittwieser, \& Janicke, 2020; Min, Xiao, Xie, Hajimirsadeghi, \& Mandayam, 2018; L.-X. Yang et al., 2018; Yasin, Liu, Li, Fatima, \& Jianmin, 2018) focusing on serious game algorithm, and methodologies along with three papers focusing on cyber security in general among the 18,000 results. In this respect, a comprehensive model on developing serious games to train users to detect, prevent, mitigate and report APT attacks is lacking in the research domain. Hence, serious games in cyber security involves a simulated malicious adversary (hacker) as a competitor of the game where success of the game depends on the player's decision-making skills.

\subsection{Decision Making in Serious Games in Cybersecurity}

Nicho et al., (2018) stated four types of decisions encountered by interconnected computer/ smartphone users in a player-hacker attack scenario. These are termed as true positive (where the user detected the threat prior to entering the system), true negative (where genuine IS process was identified and processed), false positive (where genuine IS process was identified as threat and thus stopped) and false negative (where malicious threat was identified as genuine IS process and allowed inside the network) in terms of decisions facing a user in a player-hacker attack scenario (see table 1). Here the orientation of the users namely 'True' represents correct judgement while 'False' denotes wrong judgement of the user when confronted with an IS process (the IS process can be genuine or malicious) 
Table 1. User decision models for APT threats

\begin{tabular}{|c|c|c|c|c|}
\hline \multicolumn{2}{|c|}{ Orientation } & Outcome & User assessment & Risk \\
\hline \multirow{2}{*}{ True } & Positive (TP) & Detected the threat & $\begin{array}{c}\text { Right judgement. Threat } \\
\text { prevented }\end{array}$ & Acceptable \\
\cline { 2 - 5 } & Negative (TN) & No attack took place; no alarm raised. & $\begin{array}{c}\text { Right judgement. Genuine } \\
\text { IS process identified. }\end{array}$ & Acceptable \\
\hline \multirow{2}{*}{ False } & Positive (FP) & $\begin{array}{c}\text { False alarm. Genuine IS process } \\
\text { detected as threat and stopped }\end{array}$ & Wrong judgement & $\begin{array}{c}\text { Moderate/ } \\
\text { Tolerable }\end{array}$ \\
\cline { 2 - 5 } & Negative (FN) & $\begin{array}{c}\text { APT entered the system masquerading as } \\
\text { genuine IS process/ user mistake }\end{array}$ & Wrong judgement & $\begin{array}{c}\text { Critical/ } \\
\text { Unacceptable }\end{array}$ \\
\hline
\end{tabular}

Out of the four decision scenarios, FN (represented by ' $y$ ') is critical as it is a function of SETA (represented as ' $\mathrm{x}$ ') where $\mathrm{y}=\mathrm{f}(\mathrm{x})$ and $\mathrm{y} \propto 1 / \mathrm{x}$. In a traditional SETA program, ' $\mathrm{x}$ ' must be increased substantially to decrease the incidence of ' $y$ '. However, in a cyber security serious game, a moderate increase of ' $x$ ' can result in a substantial decrease of ' $y$ ' saving the organization not only from attacks, but also savings in terms of cost and effort. Hence, consider these four decision scenarios while designing serious games for APT ensures 'effectiveness' and 'efficiency'.

\subsection{Serious Games Models}

Any model that covers the process of playing a serious game should rely on representations of the following sub-systems: the knowledge model (learning objectives), the game model (the game mechanics, challenges and content), the player model (characteristics and mental states of the player during the process of play) which all come together in the frame of operation, effectiveness (Westera, 2017). Based on the taxonomy of serious games (Laamarti et al., 2014), a holistic view of APT serious game attributes has to take into account the application, activity, modality, interaction and the environment. Furthermore, success in serious games focus on nine events of instruction by Gagne namely gain attention (GA), inform learners of the objective (LO), stimulate recall of prior learning PL), present stimulus material (SM), provide learning guidance (LG), elicit performance (EP), provide feedback (PF), assess performance (AP), and enhance retention and transfer (RT) (Hricko, 2008). Integrating these three models provide a holistic perspective of serious game for cyber security (Table 2).

Table 2. Attributes of serious game based on taxonomy (domains and methods), events and components

\begin{tabular}{|l|l|c|c|}
\hline \multicolumn{1}{|c|}{ Domains } & \multicolumn{1}{|c|}{ Methods } & Gagne' Nine events & Component Focus \\
\hline \multicolumn{2}{|c|}{ (Laamarti et al., 2014) } & (Hricko, 2008) & (Westera, 2017) \\
\hline Application area & Training \& Education & $\square$ & $\square$ \\
\hline $\begin{array}{l}\text { Activity (type of activity } \\
\text { performed by the player as } \\
\text { required by the game) }\end{array}$ & Mental & $\square$ & $\square$ \\
\hline $\begin{array}{l}\text { Modality (information } \\
\text { communication channel from } \\
\text { computer to the player) }\end{array}$ & Visual & $\square$ & $\square$ \\
\hline Interaction style (interface) & Keyboard/mouse & $\square$ & $\square$ \\
\hline $\begin{array}{l}\text { Environment (player } \\
\text { environment) }\end{array}$ & 2D/3D & $\square$ & $\square$ \\
\hline
\end{tabular}




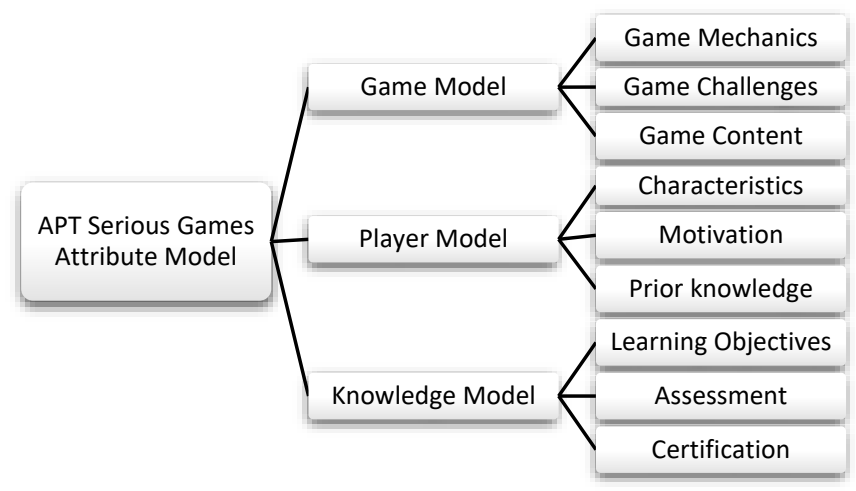

Figure 1 Serious gaming components (adapted from Westera (2017)

Table 3. GAM-APT A serious game attribute taxonomy for advanced persistent threats

\begin{tabular}{|c|c|c|}
\hline Dimensions & Game Attributes & APT Simulation Attributes/variables \\
\hline \multirow{3}{*}{ Game } & $\begin{array}{l}\text { Game mechanics: Defined "as methods } \\
\text { invoked by agents, designed for interaction } \\
\text { with the game state" which encompasses } \\
\text { those rules that are applied when the player } \\
\text { interacts with the game, as well as low-level } \\
\text { descriptions of game rules or clusters of } \\
\text { game rules (Sicart, 2008). }\end{array}$ & $\begin{array}{l}\text { Rules of play should be well explained.(Silva, } \\
\text { Maneira, \& Villachan-Lyra, 2018). Game design } \\
\text { should have complete role descriptions including } \\
\text { task responsibilities for each role (Rosenthal \& } \\
\text { Strecker, 2018). This ensures the APT game player } \\
\text { to play the game as per multiple simulated attack } \\
\text { patterns based on defense objectives of selected APT } \\
\text { threats. }\end{array}$ \\
\hline & $\begin{array}{l}\text { Game challenges: This is ensured when } \\
\text { learners are challenged slightly beyond the } \\
\text { boundaries of their abilities, while avoiding } \\
\text { both frustration and boredom (Westera, } \\
\text { 2017). }\end{array}$ & $\begin{array}{l}\text { The game becomes a challenge against time, a } \\
\text { challenge against other players and against oneself, } \\
\text { where the only thing which counts is to show to the } \\
\text { web the level of technical finesse (Soriani, Ilardo, \& } \\
\text { Falconi, 2018) of the user in DS. Multiple scenarios } \\
\text { (APT scenarios) can be created which allows for } \\
\text { players of various skill levels and backgrounds to } \\
\text { learn about information security (VanSteenburg, } \\
\text { 2017). Serious games should have various levels of } \\
\text { learning objectives and for many types of persons in } \\
\text { general (Furuichi \& Aibara, 2019). }\end{array}$ \\
\hline & $\begin{array}{l}\text { Game content: The objective of } \\
\text { gamification is to take content that is } \\
\text { typically presented to the audience, add } \\
\text { game-based elements and create a gamified } \\
\text { learning opportunity either in the form of } \\
\text { full-fledged educational game, in the form of } \\
\text { game elements wherein learners participate in } \\
\text { a story-based challenge to master the content } \\
\text { presented (Kapp, 2012). }\end{array}$ & $\begin{array}{l}\text { For each cyber security scenario, there should be two } \\
\text { scenarios, one for the intruder's perspective and the } \\
\text { other from the defender's perspective (Lu, 2018) } \\
\text { correlating with APT scenario (attack) and defender } \\
\text { mode/prescriptive actions. The four types of user } \\
\text { decision models (Table 1) in an APT scenario } \\
\text { ensures reduction of APT attacks, including SETA } \\
\text { cost and effort. }\end{array}$ \\
\hline Player & $\begin{array}{l}\text { Player characteristics: Players' } \\
\text { characteristics include players' learning } \\
\text { preferences (e.g., background knowledge, } \\
\text { interests), the gaming skills, the goals set by } \\
\text { the players and the players' motivation } \\
\text { (Katsantonis et al., 2019). }\end{array}$ & $\begin{array}{l}\text { APT vulnerabilities of users include employee } \\
\text { mistakes, lack of awareness of APT, not reading } \\
\text { communications, unethical behavior, low awareness } \\
\text { of security among non-IT staff, low motivation, } \\
\text { accessibility vs security, issues with training, not } \\
\text { reading security policies and consumer preference } \\
\text { (Nicho \& McDermott, 2019). Hence, intervention is } \\
\text { required at the dimension where the user interacts } \\
\text { with the workstation in order to assist the user to } \\
\text { make a correct decision when confronted with a } \\
\text { genuine or malicious APT vector (Nicho \& Khan, } \\
\text { 2018). }\end{array}$ \\
\hline
\end{tabular}




\begin{tabular}{|c|c|c|}
\hline & $\begin{array}{l}\text { Motivation: According to the ARCS Model, } \\
\text { four conditions are necessary for increasing } \\
\text { the motivational appeal of an instructional } \\
\text { material, namely Attention, Relevance, } \\
\text { Confidence and Satisfaction (Salameh, } \\
\text { 2019). }\end{array}$ & $\begin{array}{l}\text { Serious games can boost motivation (Lu, 2018). In } \\
\text { cybersecurity awareness programs, engagement is an } \\
\text { important factor for activating attention and creating } \\
\text { interest in changing behavior (Salameh, 2019); the } \\
\text { APT game has to be tailored to ensure relevance to } \\
\text { the day-to-day work of the participating } \\
\text { professionals (Gasiba, Lechner, Rezabek, \& Pinto- } \\
\text { Albuquerque, 2020); APT games can be created } \\
\text { where, "users became more confident about their } \\
\text { judgments after the game or the tutorial conditions" } \\
\text { (Sheng et al., 2007); "when designing tools to } \\
\text { educate people, it is highly recommended to measure } \\
\text { users' satisfaction" (Micallef \& Arachchilage, 2017) } \\
\text { which translates to feedback. }\end{array}$ \\
\hline & $\begin{array}{l}\text { Prior knowledge: Refers to the learners' } \\
\text { knowledge states where a deficit results in } \\
\text { increased challenge (Westera, 2017). }\end{array}$ & $\begin{array}{l}\text { Adaptation of APT games could be through the } \\
\text { personalization of content to the user's knowledge } \\
\text { and goals (Streicher \& Smeddinck, 2016) with } \\
\text { different levels of game difficulty. "Splitting content } \\
\text { into levels, scenarios, or modules allows for players } \\
\text { to come back later to reinforce previous lessons or } \\
\text { learn new material that they have not played before" } \\
\text { (VanSteenburg, 2017). }\end{array}$ \\
\hline \multirow{3}{*}{ Knowledge } & $\begin{array}{l}\text { Learning objectives: A serious game will } \\
\text { have learning objective for players in terms } \\
\text { of knowledge, skills and competencies to be } \\
\text { achieved (Westera, 2017). }\end{array}$ & $\begin{array}{l}\text { Clear and worthwhile objectives in game scenarios } \\
\text { are necessary to create an effective serious game for } \\
\text { cybersecurity training and awareness. Furthermore, } \\
\text { serious games should contain easy to understand } \\
\text { unambiguous objectives, synchronize learning and } \\
\text { gameplay objectives (VanSteenburg, 2017). Thus, "a } \\
\text { game would consistently fulfil cyber security } \\
\text { strategies' objectives in terms of education and } \\
\text { awareness" (Le Compte, Elizondo, \& Watson, 2015). } \\
\text { Since APT uses multiple methods, defined specific } \\
\text { objectives for each scenario provides focus on the } \\
\text { learning objective. }\end{array}$ \\
\hline & $\begin{array}{l}\text { Assessment: Game assessment imply that the } \\
\text { game matches technical and pedagogic } \\
\text { expectations, while maximizing players' } \\
\text { engagement and enjoyment (Le Compte et } \\
\text { al., 2015). }\end{array}$ & $\begin{array}{l}\text { Serious games should provide continuous assessment } \\
\text { immediate feedback regarding the progress toward } \\
\text { those objectives (VanSteenburg, 2017). Gamification } \\
\text { elements, including clear goals, points, } \\
\text { achievements, feedback and leader boards, increase } \\
\text { motivation (Alqahtani \& Kavakli-Thorne, 2020). } \\
\text { Provision of assessment and feedback regarding } \\
\text { success or failure during each APT gaming scenario } \\
\text { enhances player knowledge. }\end{array}$ \\
\hline & $\begin{array}{l}\text { Certification: This refers to positive } \\
\text { reinforcement in which rewards were given } \\
\text { after a fixed number of correct responses } \\
\text { (Nagle, Wolf, Riener, \& Novak, 2014). }\end{array}$ & $\begin{array}{l}\text { Motivation for the games is either recognition } \\
\text { (financial or other incentives like prizes for first, } \\
\text { second and third places in the competition) or } \\
\text { certification to enhance your professional career. } \\
\text { (Nagarajan, Allbeck, Sood, \& Janssen, 2012). } \\
\text { Continuous improvement ca be gained through } \\
\text { tangible awards after the success of any game } \\
\text { scenario. }\end{array}$ \\
\hline
\end{tabular}

\section{CONCLUSION}

The increase in APT attacks using dynamic, novel and sophisticated methods targeting organizational networks via inadvertent user mistakes has prompted organizations to focus aggressively on SETA training. Serious games come with the added advantage of encompassing the entire organizational users in a short time with increased effectiveness, less cost, time and effort. Hence, APT where users have to be trained on 
appropriate decision making when confronted with multiple attack scenarios. In this respect, our Game Attribute Taxonomy for Advanced Persistent Threats (GAM-APT) provides the methodology for serious game developers to develop games that target internetworked computer users in organizations as well as work from home users. While research and industry has targeted interconnected computer users with simulated games on different aspects of cyber security, this is the first such model that demonstrates the essential attributes of a serious gaming model for APT scenarios, where the user/trainee holds the key to open a vulnerability or demonstrate the ability to detect, prevent, mitigate and/or report the simulated malicious actor. Limitations of this research focus on three areas for which subsequent research is required. First, researchers need to ascertain the cause and effect of the variables in the taxonomy to ascertain the precursor events. Identifying the pre cursor events for game attractiveness and success can enhance game effectiveness. Second, this taxonomy needs to be validated with experts in the cybersecurity field to bring out its strength and weakness. Third, the taxonomy needs to be translated into a prototype and tested on an experimental group to evaluate its effectiveness. We hope that this model will serve as a baseline for serious game developers in creating training simulations.

\section{REFERENCES}

Alqahtani, H., \& Kavakli-Thorne, M. (2020). Design and Evaluation of an Augmented Reality Game for Cybersecurity Awareness (CybAR). Information, 11(2), 121.

Alshamrani, A., Myneni, S., Chowdhary, A., \& Huang, D. (2019). A survey on advanced persistent threats: Techniques, solutions, challenges, and research opportunities. IEEE Communications Surveys \& Tutorials, 21(2), 1851-1877.

Boyle, E. A., MacArthur, E. W., Connolly, T. M., Hainey, T., Manea, M., Kärki, A., \& Van Rosmalen, P. (2014). A narrative literature review of games, animations and simulations to teach research methods and statistics. Computers \& Education, 74, 1-14.

Clark, C. A. (1970). Serious games. Nueva York: Viking.

Connolly, T. M., Boyle, E. A., MacArthur, E., Hainey, T., \& Boyle, J. M. (2012). A systematic literature review of empirical evidence on computer games and serious games. Computers \& Education, 59(2), 661-686.

Feng, S., Xiong, Z., Niyato, D., \& Wang, P. (2019). Dynamic resource management to defend against advanced persistent threats in fog computing: A game theoretic approach. IEEE Transactions on Cloud Computing.

Furnell, S. (2013). Still on the hook: the persistent problem of phishing. Computer Fraud \& Security, 2013(10), 7-12.

Furuichi, M., \& Aibara, M. (2019). A Challenge of Developing Serious Games to Raise the Awareness of Cybersecurity Issues. Paper presented at the DiGRA Conference.

Gasiba, T., Lechner, U., Rezabek, F., \& Pinto-Albuquerque, M. (2020). Cybersecurity Games for Secure Programming Education in the Industry: Gameplay Analysis. Paper presented at the First International Computer Programming Education Conference (ICPEC 2020).

Hart, S., Margheri, A., Paci, F., \& Sassone, V. (2020). Riskio: A Serious Game for Cyber Security Awareness and Education. Computers \& Security, 101827.

Heldal, I., Wijkmark, C. H., \& Pareto, L. (2016). Simulation and serious games for firefighter training: Challenges for effective use. Paper presented at the Norsk konferanse for organisasjoners bruk at IT.

Hricko, M. (2008). Gagne's Nine Events of Instruction Encyclopedia of Information Technology Curriculum Integration (pp. 353-356): IGI Global.

Huang, L., \& Zhu, Q. (2020). A dynamic games approach to proactive defense strategies against advanced persistent threats in cyber-physical systems. Computers \& Security, 89, 101660.

Kapp, K. M. (2012). The gamification of learning and instruction: game-based methods and strategies for training and education: John Wiley \& Sons.

Katsantonis, N. M., Kotini, I., Fouliras, P., \& Mavridis, I. (2019). Conceptual framework for developing cyber security serious games. Paper presented at the 2019 IEEE Global Engineering Education Conference (EDUCON).

Laamarti, F., Eid, M., \& El Saddik, A. (2014). An overview of serious games. International Journal of Computer Games Technology, 2014.

Le Compte, A., Elizondo, D., \& Watson, T. (2015). A renewed approach to serious games for cyber security. Paper presented at the 2015 7th International Conference on Cyber Conflict: Architectures in Cyberspace.

Lu, Y. (2018). CyberCraft, a security serious game. (PhD), Politecnico di Torino. Retrieved from https://webthesis.biblio.polito.it/9474/ 
Luh, R., Temper, M., Tjoa, S., Schrittwieser, S., \& Janicke, H. (2020). PenQuest: a gamified attacker/defender meta model for cyber security assessment and education. Journal of Computer Virology and Hacking Techniques, 16(1), 19-61.

Micallef, N., \& Arachchilage, N. A. G. (2017). Involving users in the design of a serious game for security questions education. arXiv preprint arXiv:1710.03888.

Min, M., Xiao, L., Xie, C., Hajimirsadeghi, M., \& Mandayam, N. B. (2018). Defense against advanced persistent threats in dynamic cloud storage: A colonel blotto game approach. IEEE Internet of Things Journal, 5(6), 4250-4261.

Nagarajan, A., Allbeck, J. M., Sood, A., \& Janssen, T. L. (2012). Exploring game design for cybersecurity training. Paper presented at the 2012 IEEE International Conference on Cyber Technology in Automation, Control, and Intelligent Systems (CYBER).

Nagle, A., Wolf, P., Riener, R., \& Novak, D. (2014). The use of player-centered positive reinforcement to schedule in-game rewards inreases enjoyment and performance in a serious game. International Journal of Serious Games, 1(4), 35-47.

Nicho, M., \& Khan, S. N. (2018). A decision matrix model to identify and evaluate APT vulnerabilities at the user plane. Paper presented at the 2018 41st International Convention on Information and Communication Technology, Electronics and Microelectronics (MIPRO).

Nicho, M., \& McDermott, C. D. (2019). Dimensions of 'Socio'Vulnerabilities of Advanced Persistent Threats. Paper presented at the 2019 International Conference on Software, Telecommunications and Computer Networks (SoftCOM).

Parthy, P. P., \& Rajendran, G. (2019). Identification and prevention of social engineering attacks on an enterprise. Paper presented at the 2019 International Carnahan Conference on Security Technology (ICCST).

Rodríguez-Corzo, J. A., Rojas, A. E., \& Mejía-Moncayo, C. (2018). Methodological model based on Gophish to face phishing vulnerabilities in SME. Paper presented at the 2018 ICAI Workshops (ICAIW).

Rosenthal, K., \& Strecker, S. (2018). Business Process Modelling as Serious Game: Findings From a Field Study. Paper presented at the ECIS 2018, Portsmouth, UK.

Salameh, R. (2019). The Relationship between Engagement Levels and Players' Intended Behaviors in Game-Based Training for Cybersecurity. Southern Illinois University at Carbondale.

Saunders, J. H. (2001). The case for modeling and simulation of information security. Paper presented at the Computer Security Institute Conference, http://www. johnsaunders. com/papers/securitysimulation. htm.

Sheng, S., Magnien, B., Kumaraguru, P., Acquisti, A., Cranor, L. F., Hong, J., \& Nunge, E. (2007). Anti-phishing phil: the design and evaluation of a game that teaches people not to fall for phish. Paper presented at the Proceedings of the 3rd symposium on Usable privacy and security.

Sicart, M. (2008). Defining Game Mechanics. The International Journal of Computer Game Research, 8(2).

Silva, M. C. A. P., Maneira, A., \& Villachan-Lyra, P. (2018). Digital Educational Games: Inclusive Design Principles for Children with ADHD. Proceedings of Play2Learn 2018, 30.

Sonawane, K. (2017). Serious Games Market by User Type. Retrieved from https://www.alliedmarketresearch.com/serious-gamesmarket\#: :text=The\%20global\%20serious\%20games\%20market,designed\%20for\%20education\%20with\%20fun.

Soriani, A., Ilardo, M., \& Falconi, A. (2018). Videogames, Violence and Aggressive Behavior: an Educational Proposal. Proceedings of Play2Learn 2018, 11.

Streicher, A., \& Smeddinck, J. D. (2016). Personalized and adaptive serious games Entertainment Computing and Serious Games (pp. 332-377): Springer.

Tioh, J.-N., Mina, M., \& Jacobson, D. W. (2017). Cyber security training a survey of serious games in cyber security. Paper presented at the 2017 IEEE Frontiers in Education Conference (FIE).

Van Voorhis, V., \& Paris, B. (2019). Simulations and Serious Games: Higher Order Thinking Skills Assessment. Journal of Applied Testing Technology, 20(S1), 35-42.

VanSteenburg, M. (2017). Applications of Serious Gaming to Cybersecurity Training and Awareness. Utica College.

Westera, W. (2017). How people learn while playing serious games: A computational modelling approach. Journal of Computational Science, 18, 32-45.

Yang, L.-X., Li, P., Zhang, Y., Yang, X., Xiang, Y., \& Zhou, W. (2018). Effective repair strategy against advanced persistent threat: A differential game approach. IEEE Transactions on Information Forensics and Security, 14(7), $1713-1728$

Yang, L. (2018). CyberCraft, a security serious game. POLITECNICO DI TORINO, Torino.

Yasin, A., Liu, L., Li, T., Fatima, R., \& Jianmin, W. (2018). Improving software security awareness using a serious game. IET Software, 13(2), 159-169. 